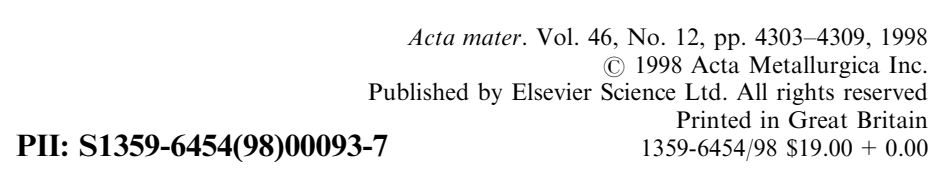

\title{
IN SITU DIMENSIONAL CHANGES OF POWDER INJECTION-MOLDED COMPACTS DURING SOLVENT DEBINDING
}

\author{
H.-K. LIN and K.-S. HWANG $\dagger$ \\ Institute of Materials Science and Engineering, National Taiwan University, No. 1, Roosevelt Rd., \\ Sec. 4, Taipei 106, Taiwan, R.O.C.
}

(Received 13 December 1997; accepted 2 March 1998)

\begin{abstract}
Defects such as cracking, slumping, and sagging are frequently found in powder injectionmolded (PIM) compacts. These defects are partly related to the swelling of the binders during solvent debinding. However, little quantitative analysis has been reported to date. The in situ length changes of PIM specimens during debinding were measured in this study using a laser dilatometer designed by the authors specifically for these experiments. A total linear expansion from 0.5 to $2 \%$ was observed and was influenced by the binder, the solvent type, and the debinding temperature. This expansion is attributed to the interaction between the solvent and the binder, particularly the insoluble backbone binder components such as low-density polyethylene and polypropylene. These in situ measurements on the length and temperature changes help explain how the defects formed during debinding. Based on the results observed, guidelines for designing binders and debinding schedules are recommended. (C) 1998 Acta Metallurgica Inc. Published by Elsevier Science Ltd. All rights reserved.
\end{abstract}

\section{INTRODUCTION}

The solvent debinding process was introduced to the powder injection molding (PIM) industries during the 1980s. The first step of this process is to extract soluble binder components by using solvents such as heptane or hexane. The remaining insoluble binders are then removed in a subsequent thermal debinding step $[1,2]$. Previous studies indicated that the solvent extraction process consisted of four stages [3]. First, solvent molecules penetrate into the binder, producing swollen gels. When the binder-solvent interactions are strong enough, the gels gradually disintegrate into a true solution [4]. The solution then diffuses toward the surface, and finally, the solution is removed from the surface. The limiting step was found to be the outward diffusion of the binder-solvent solution. To understand the debinding kinetics, models and diffusion equations similar to the decarburization of steels were developed and were validated by experimental data $[3,5]$.

The microstructure evolution in the compact was also examined by Hwang and Hsieh using mercury porosimetry data and scanning electron micrographs [6]. The results of that study confirmed that the binder dissolution starts from the surface and progresses inward. The binder dissolution leaves interpenetrating pore channels which are used by the decomposed gas to escape during the subsequent thermal debinding.

$\dagger$ To whom all correspondence should be addressed.
This solvent debinding process shortens the debinding cycle significantly and has therefore been quickly accepted by the industry. Nevertheless, this process, when not properly executed, may result in cracking, distortion, and slumping $[3,7,8]$. These defects were explained briefly by Lin and German, who attributed this problem to binder swelling and binder softening [3]. However, quantitative analysis on these phenomena and their relation to the dimensional changes of PIM compacts has not been reported to date. The main technical difficulty has been to find a reliable method to monitor the in situ changes in length. This is because PIM specimens become soft when they are in contact with the solvent, which makes in situ measurement with mechanical devices such as micrometers or calipers almost impossible. If specimens are measured after they are removed from the solvent bath, the readings can be misleading because the dimension of the specimen may change due to the temperature change, solvent evaporation, and handling. Thus, the main objective of this study was to develop a method to measure the in situ dimensional changes of the specimen in the solvent bath without actually making contact with the compact. Hopefully, the debinding behavior of PIM compacts and its relationship to defects can be better understood.

In this study, two solvents, five binder compositions, and four debinding temperatures were used, and their effects on the debinding behavior were compared. Based on these observations, the amount of swelling and distortion caused by each binder type should be considered in addition to the existing 
Table 1. Characteristics of carbonyl iron powders used in this study

\begin{tabular}{|c|c|c|}
\hline \multicolumn{2}{|l|}{ Powder Type } & $\begin{array}{c}\text { Carbonyl iron powder, } \\
\text { (CIP-S-1641) }\end{array}$ \\
\hline \multicolumn{2}{|l|}{ Supplier } & ISP Corp. \\
\hline \multicolumn{2}{|c|}{ Average particle size (F.S.S.S.) } & $4.6 \mu \mathrm{m}$ \\
\hline \multicolumn{2}{|c|}{ Surface area } & $0.77 \mathrm{~m}^{2} / \mathrm{g}$ \\
\hline \multicolumn{2}{|l|}{ Pycnometer density } & $7.542 \mathrm{~g} / \mathrm{cm}^{3}$ \\
\hline \multicolumn{2}{|c|}{ Angle of repose } & $50^{\circ}$ \\
\hline \multicolumn{2}{|l|}{ Tap density } & $4.16 \mathrm{~g} / \mathrm{cm}^{3}$ \\
\hline \multirow[t]{3}{*}{ Chemistry (wt $\%$ ) } & $\mathrm{C}$ & 0.786 \\
\hline & $\mathrm{O}$ & 0.957 \\
\hline & $\mathrm{N}$ & 0.721 \\
\hline
\end{tabular}

guidelines for binder design and for selecting the debinding schedule. Solutions to alleviate defects which appear during debinding are also recommended.

\section{EXPERIMENTAL}

Carbonyl iron powder was used in this study to fabricate injection-molded specimens. It has a spherical shape, fine particle size, and high interparticle friction. Its characteristics are given in Table 1. To prepare the feedstock, iron powders were kneaded with polymeric binders in a weight ratio of 92:8. The polymeric binder consisted of low-density polyethylene (LDPE) or polypropylene (PP), paraffin wax (PW), and stearic acid (SA). The characteristics of these binder components are given in Table 2. Table 3 lists the five compositions of the binder systems examined in this study.

After being kneaded and granulated, the feedstock was molded into rectangular specimens of $100 \mathrm{~mm} \times 12 \mathrm{~mm} \times 4 \mathrm{~mm}$. The solvent debinding was carried out by immersing specimens in hexane or heptane, which have boiling points of $68^{\circ} \mathrm{C}$ and $98^{\circ} \mathrm{C}$, respectively.

Figure 1 illustrates the setup of the laser dilatometer which was used to measure the changes in length of the compacts. The specimen was held fixed by set screws at the holder end, while the other end was free to move. At the free end, a length indicator plate made of aluminum foil was attached like a periscope so that the movement of the specimen, which was immersed in the solvent bath, could be detected by the laser sensor. In order to get good-quality signals, a steel plate was placed below the zone where the laser beam passed so that the laser beam would not be disturbed by the solvent or the water vapor. To reduce friction, alumina rollers were placed under the specimen. A thermocouple was inserted into the compact to
Table 3. The compositions of the binder system examined in this study

\begin{tabular}{lccccc}
\hline \multirow{2}{*}{$\begin{array}{l}\text { Binder } \\
\text { components }\end{array}$} & \multicolumn{5}{c}{ Specimen number } \\
\cline { 2 - 6 } & 1 & 2 & 3 & 4 & 5 \\
\hline PP & 30 & 40 & - & - & - \\
LDPE & - & - & 30 & 40 & 50 \\
PW & 65 & 55 & 65 & 55 & 45 \\
SA & 5 & 5 & 5 & 5 & 5 \\
\hline
\end{tabular}

record the temperature change. As the specimen and the chamber were heated to the desired temperature by the constant temperature bath, solvent which had been preheated to the same temperature as the specimen was introduced into the specimen chamber from the solvent tank. The immersion and retrieval of specimens were simulated by introducing and draining the solvent into and out of the specimen chamber.

To measure the distortion of compacts, $100 \mathrm{~mm}$ long specimens were supported by two ridges $80 \mathrm{~mm}$ apart, each located $10 \mathrm{~mm}$ from its respective end. The degree of distortion was determined by the sagging distance, which was defined as the relative height between the center and the two ends. To determine the melting point of each pure binder component and the mixed feedstock, a differential scanning calorimeter (DSC) was used. The testing was carried out in nitrogen using a heating rate of $10^{\circ} \mathrm{C} / \mathrm{min}$.

\section{RESULTS}

To understand the capability of the laser dilatometer, the dimensional change of a pure copper block was measured. Figure 2 shows that the specimen, which was originally at $25^{\circ} \mathrm{C}$, expanded approximately $0.025 \%$ after the preheated $40^{\circ} \mathrm{C}$ water was introduced into the chamber and the system reached equilibrium. This small amount of expansion agreed well with the amount calculated from the thermal expansion coefficient of copper. Slight fluctuation, which was caused by the vibration of the system, the flow of water, and the noise from the electronics, was noticed. This fluctuation was, however, insignificant compared to the dimensional changes of molded specimens, as will be reported later.

Figure 3 shows the effect of debinding temperature on the length of the No. 1 specimen, the binder which consisted of $30 \mathrm{wt} \% \mathrm{PP}, 65 \mathrm{wt} \% \mathrm{PW}$, and $5 \mathrm{wt} \%$ SA. The specimen length increased as debinding time and temperature were increased. At

Table 2. Characteristics of binder components used in this study

\begin{tabular}{lccc}
\hline Binder type & Melting point $\left({ }^{\circ} \mathrm{C}\right)$ & Density $\left(\mathrm{g} / \mathrm{cm}^{3}\right)$ & Supplier \\
\hline Low density polyethylene & 99 & 0.916 & USIFE Co. \\
Polypropylene & 169 & 0.903 & Taiwan P.P. Co. \\
Paraffin wax & 70 & 0.912 & Nippon Seiro Co. \\
Stearic acid & 72 & 0.962 & Nacalai Tesque Inc. \\
\hline
\end{tabular}




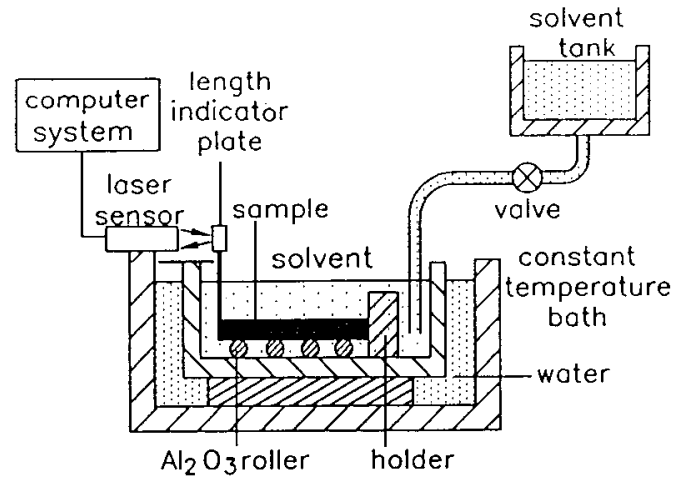

Fig. 1. The schematics of the laser dilatometer which was used to measure the in situ changes in length of PIM compacts during solvent debinding.

$60^{\circ} \mathrm{C}$, the swelling curve reached a plateau of about $0.75 \%$ in about $2000 \mathrm{~s}$. As the heptane temperature decreased to $30^{\circ} \mathrm{C}$, the amount of expansion decreased to $0.25 \%$. It was also noted that the curves showing the amount of swelling which occurred at $30^{\circ} \mathrm{C}$ and $40^{\circ} \mathrm{C}$ crossed each other. This initiated another test on five debinding runs, and the swelling curves at $40^{\circ} \mathrm{C}$ were non-repeatable, as shown in Fig. 4. This implies that the dimensions of the specimen are difficult to control because of the unpredictable debinding behavior. When the PP content increased to $40 \mathrm{wt} \%$ (specimen No. 2), the amount of expansion increased slightly and the curves did not intersect, as shown in Fig. 5, and were repeatable.

When the $40 \mathrm{wt} \%$ PP was replaced by $40 \mathrm{wt} \%$ LDPE (specimen No. 4), the amount of swelling further increased to about $1.8 \%$ at $60^{\circ} \mathrm{C}$, as shown in Fig. 6. This difference in swelling is conceivable because LDPE has lower crystallinity, lower melting point, lower tensile strength, and smaller difference in the solubility parameter with the heptane. Figure 7 illustrates the effect of the amount of backbone binder on swelling. It shows that as the LDPE increased from $30 \mathrm{wt} \%$ to 40 or $50 \mathrm{wt} \%$, the speci-

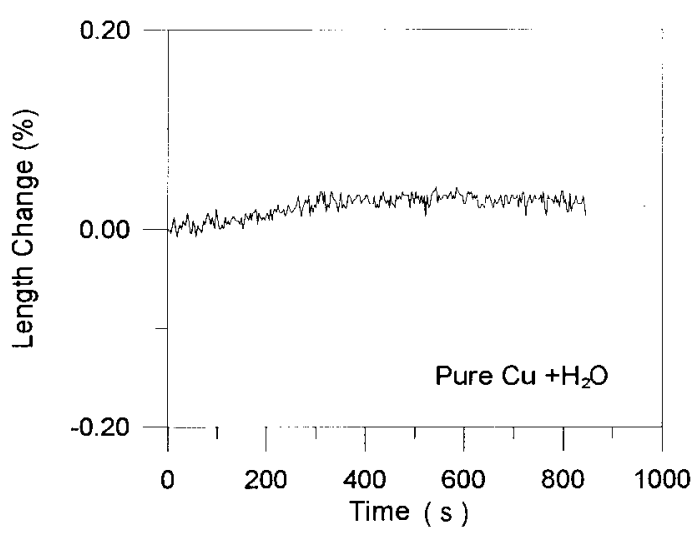

Fig. 2. The dimensional change of a pure copper block measured by the laser dilatometer when $40^{\circ} \mathrm{C}$ water was introduced into the $25^{\circ} \mathrm{C}$ specimen chamber.

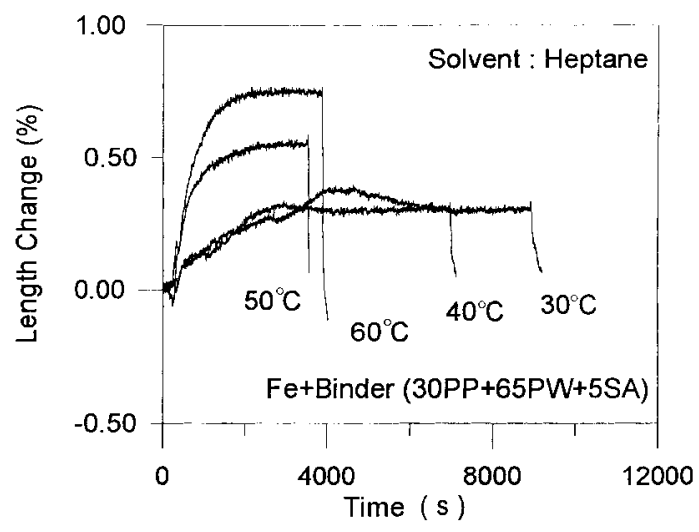

Fig. 3. The length of specimen No. 1 $(30 \% \mathrm{PP}+65 \% \mathrm{PW}+5 \% \mathrm{SA})$ when immersed in heptane increases with increasing debinding time and temperature.

men length increased. This result exhibits the same trend as those results given in Figs 3 and 5, in which the amount of swelling increases as the PP content in the binder increases from 30 to $40 \mathrm{wt} \%$.

All the above experiments were carried out using heptane as the solvent. When hexane was used, the amount of expansion further increased, as shown in Table 4. The specimens were immersed in the $40^{\circ} \mathrm{C}$ hexane bath for $6000 \mathrm{~s}$. This difference in length changes is very likely since hexane molecules are smaller than heptane molecules and thus can diffuse faster into the binder, producing swollen gels.

To better understand the reaction between each binder component and the solvent, specimens made of pure PP and LDPE were immersed in hexane. Figure 8 shows that both PP and LDPE swelled, with LDPE doing so more significantly. Similar experiments were also carried out using heptane, and the same trend was observed. For pure paraffin and stearic acid, which dissolve easily in heptane and hexane, a volumetric flask was used instead of the laser dilatometer to record the volume change of the solvent-binder system prior to and after the binder dissolution. The dissolution of PW and SA

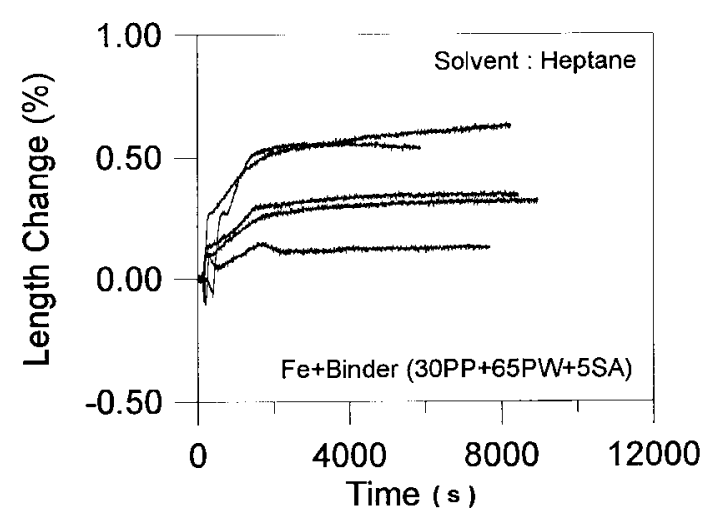

Fig. 4. The expansion curves of five independent debinding runs showing the poor repeatability of No. 1 specimens, which contain $30 \%$ PP. 


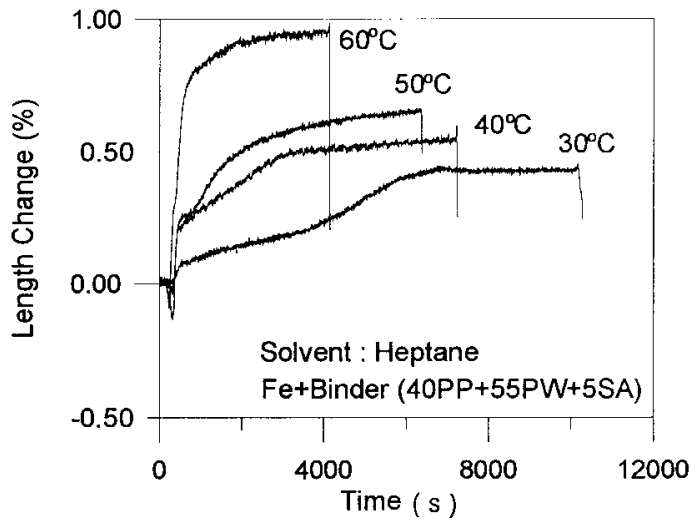

Fig. 5. Compared to Fig. 3, the amount of expansion of molded specimens increases when the PP content increases from $30 \%$ to $40 \%$.

causes the liquid level to move up and down in the bottle neck. This method, although not as sensitive as the laser dilatometer, still provides semi-quantitative information. The results show that the total increase in volume of the solvent-binder solution containing PW and SA, as shown in Table 5, was even greater than the volume increase of solvents which contained pure PP and LDPE.

Since the difficulty of controlling the final dimension increases in proportion to the amount of expansion during debinding, it is desirable to alleviate swelling during debinding. Therefore, based on the results shown in Table 5, it would be intuitive to think that less PW and SA should be used in the specimen. However, a change in the binder composition may affect the shape retention capability and the debinding rate. Figure 9 shows that as the amount of PW decreased, the degree of debinding completion, which was defined as the percentage of the soluble binder that had been extracted, also decreased. It was originally expected that as the amount of soluble binder in the compact was decreased, the solvent debinding time required to remove all soluble binder would also be reduced.

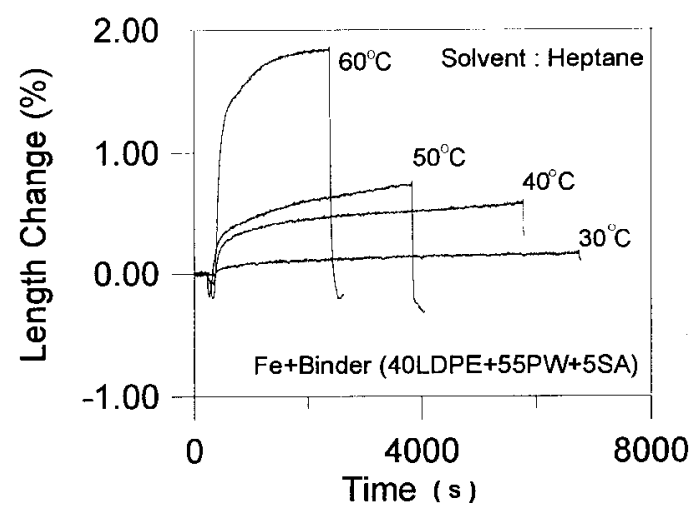

Fig. 6. Specimens that contain LDPE swell more significantly than those containing PP, as shown in Fig. 5.

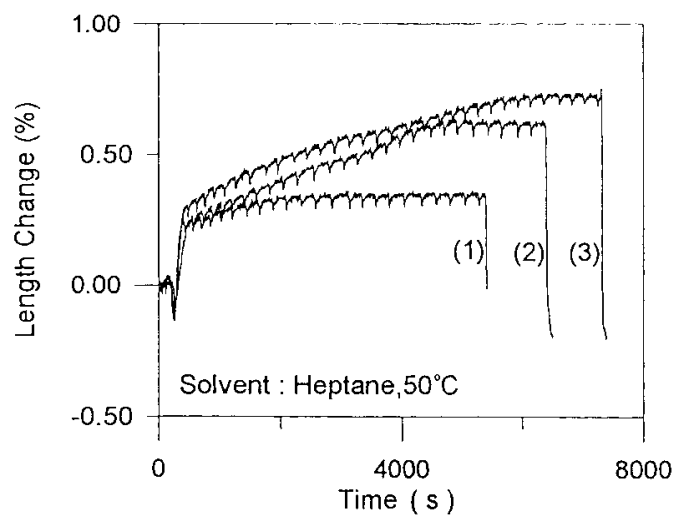

(1): Fe+Binder(3OLDPE+6SPW+5SA)

(2) : Fe+Binder(40LDPE+55PW+5SA)

(3) : Fe+Binder(5OLDPE+45PW+5SA)

Fig. 7. The amount of expansion of LDPE-containing specimens increases with increasing LDPE content.

This, however, is contrary to the curves shown in Fig. 9. It is very likely that, with less soluble binder, the pore channels became less interconnected. Moreover, the swollen backbone binders may clog the pores and thus the debinding rate was impeded. This result suggested that more $\mathrm{PW}$ and $\mathrm{SA}$ is needed if a short debinding cycle is desired.

To better understand the swelling behavior, the in situ specimen temperature was also recorded. Figure 10 shows the in situ length and temperature change in a debinding run. In this test, the specimens expanded significantly at the beginning as the $50^{\circ} \mathrm{C}$ solvent was introduced into the $18^{\circ} \mathrm{C}$ specimen chamber. This expansion is mainly caused by the swelling of the binder, as was detected in specimens which were examined isothermally, as shown from Figs 3-7. As the temperature stabilized at $50^{\circ} \mathrm{C}$, the specimen continued to swell slowly. At the end of the run, as the solvent was drained from the bath, sharp decreases in temperature and length were recorded. The $42^{\circ} \mathrm{C}$ core temperature of the specimen, which was lower than the ambient temperature, indicated that evaporation of the trapped solvent occurred and some heat was drawn from the specimen. After the sharp decrease in length, the specimen expanded as the specimen temperature rose back to the chamber temperature of $49^{\circ} \mathrm{C}$. This is possibly because there was still some solvent remaining and the backbone binder swelled again due to the same temperature effect as was described earlier. As the specimen temperature stabilized at $49^{\circ} \mathrm{C}$, the specimen length decreased again. This

Table 4. A comparison of the effects of solvent type showing that hexane causes more swelling than heptane

\begin{tabular}{llcc}
\hline Sample no. & Binder composition & $\begin{array}{c}\text { in } 40{ }^{\circ} \mathrm{C} \\
\text { heptane }\end{array}$ & $\begin{array}{c}\text { in } 40{ }^{\circ} \mathrm{C} \\
\text { hexane }\end{array}$ \\
\hline 1 & $40 \mathrm{PP}+55 \mathrm{PW}+5 \mathrm{SA}$ & $0.52 \%$ & $0.70 \%$ \\
2 & $40 \mathrm{LDPE}+55 \mathrm{PW}+5 \mathrm{SA}$ & $0.53 \%$ & $0.87 \%$ \\
\hline
\end{tabular}



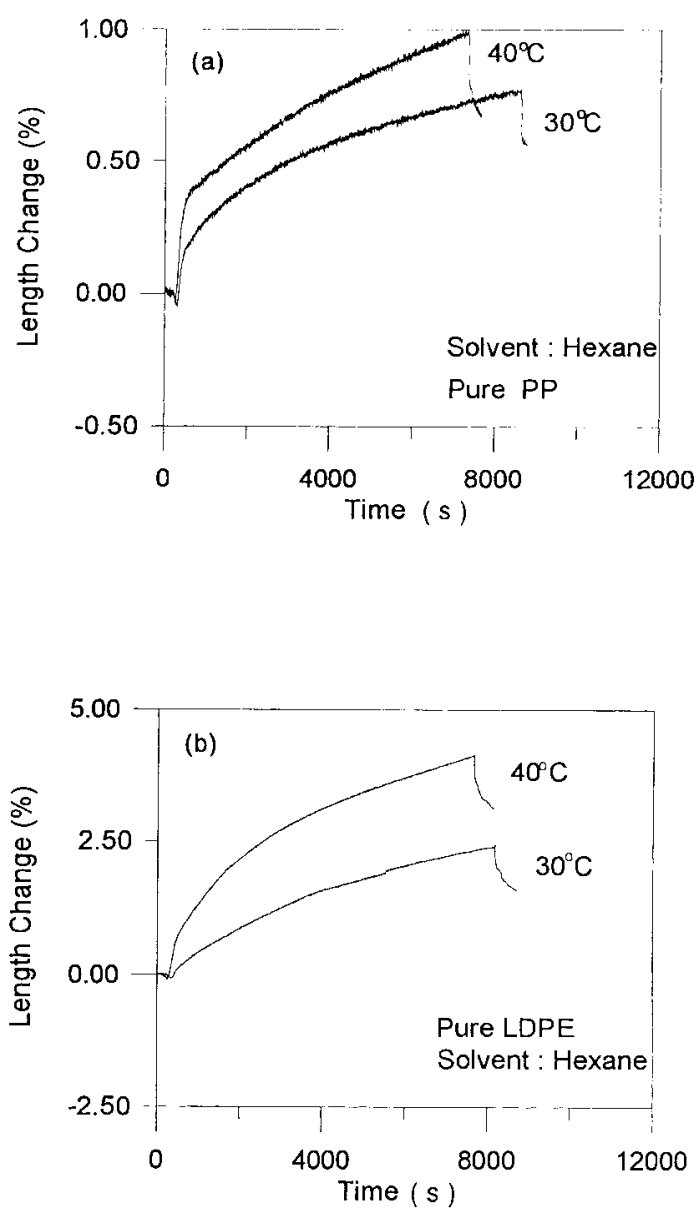

Fig. 8. The length change of (a) pure PP and (b) pure LDPE specimens when immersed in hexane.

shrinkage, like the one that occurred during the solvent draining, is possibly attributed to the loss of the solvent which causes shrinking of the swollen backbone binder.

To design an optimum debinding schedule, both the length of the debinding time and the susceptibility to defect formation must be considered. Figure 11 shows the sagging distance of No. 4 specimens which contain $40 \mathrm{wt} \%$ LDPE, $55 \mathrm{wt} \%$ PW and $5 \mathrm{wt} \% \mathrm{SA}$ in the binder. Specimens sagged significantly at $50^{\circ} \mathrm{C}$ and $60^{\circ} \mathrm{C}$, but not at $40^{\circ} \mathrm{C}$ and $45^{\circ} \mathrm{C}$. Considering both the debinding rate and the amount of distortion, the best debinding temperature selected in this study for sample No. 4 was therefore $45^{\circ} \mathrm{C}$.

Table 5. The amount of volume expansion of PP, LDPE, PW, and SA after being immersed in heptane for $1 \mathrm{~h}$ at $60^{\circ} \mathrm{C}$

\begin{tabular}{ll}
\hline Binder components & $\%$ \\
\hline PP & 3.5 \\
LDPE & 4.5 \\
PW & 9.0 \\
SA & 6.5 \\
\hline
\end{tabular}

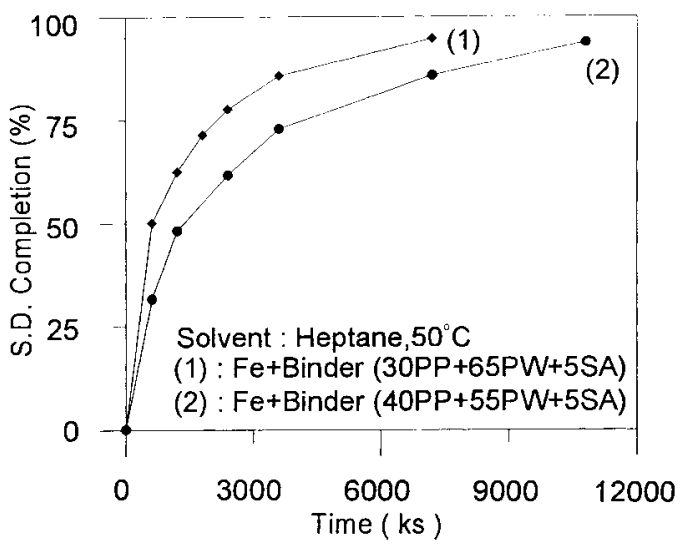

Fig. 9. The weight-loss curves of specimens show that the more soluble are binder components in the specimen, the faster the debinding rate.

\section{DISCUSSION}

From the volume expansion data, as given in Table 5, it can be argued that, in addition to the swelling of LDPE and PP, soluble binder components, namely PW and SA, will also cause swelling, and their effects should be even greater. However, Figs 3, 5 and 7 show that the use of greater amounts of PW and SA actually results in less swelling. Moreover, Fig. 9 shows that the debinding rate increases as the amount of PW and SA increases. All these seem to be contradictory to the expectations.

This is because unlike LDPE and PP, which form a swollen gel in heptane and hexane, PW and SA form liquid solutions. When the expanded solution is in the liquid form, the solution will be forced out of the compact due to the constraint of the powder and the swollen gel which is formed from the backbone binder. Thus, little swelling and stress was caused by the soluble binder. Moreover, due to the outward flow of the solution, a fast debinding rate was observed in the early stage. Another possible reason for the fast debinding rate in compacts with more PW and SA is that there are more interconnected pore channels through which dissolved solution can diffuse to the surface. In contrast, with a large amount of backbone binder, there are fewer channels; in addition, the swollen gel may also clog these channels. Thus the diffusion of the binder-solvent solution or the debinding rate is slower.

It is noted in Fig. 10 that a large amount of shrinkage and temperature drop occur at the end of the debinding run. This shrinkage was caused mainly by the loss of the solvent from the swollen gel in the compact. Since PIM compacts usually have complicated shapes, this sudden change in dimension could cause cracking or distortion at places where sections with different thickness meet. Thus, to avoid these defects, it would be preferable to cool specimens in the solvent before they are taken out of the bath. This will reduce the shrink- 


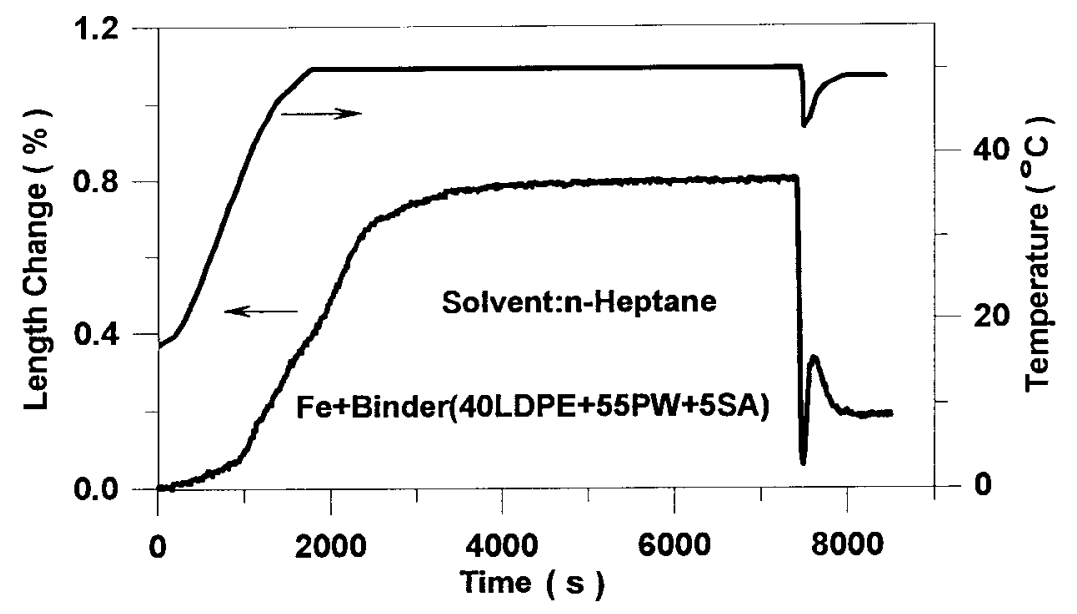

Fig. 10. The changes in temperature and length of specimens which were under solvent debinding showing sharp changes at the end of the run.

age rate because the amount of expansion decreases as the debinding temperature decreases as shown in Figs 3, 5 and 6.

Selections of the optimum binder type, binder ratio, and debinding temperature have always been a difficult job in developing the solvent debinding process for PIM practitioners. Several principles and criteria have been established in previous literature $[1,8-10]$. The results on swelling and distortion observed in this study could provide two more guidelines.

\subsection{Swelling}

As is well known, increasing the amount of PE or PP increases the difficulty of the molding. The results in Section 3 also show that as the amount of $\mathrm{PE}$ and PP increase, the swelling becomes more significant and the debinding rate decreases. Thus, it would be intuitive to use as little backbone binder as possible. However, there must be a minimum, otherwise, there will not be enough backbone binder to prevent compacts from slumping and distort-

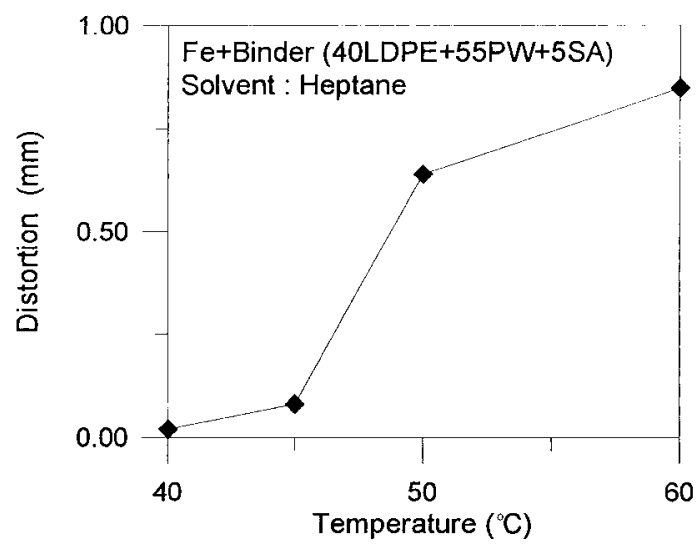

Fig. 11. The degree of sagging of specimens at different debinding temperatures. ing. When the above results were reviewed, it was noticed that in Fig. 3, the swelling curves at $30^{\circ} \mathrm{C}$ and $40^{\circ} \mathrm{C}$ of specimen No. 1 intersect. In addition, the repeatability of the swelling curves is very poor, as shown in Fig. 4. These results indicate that the amount of PP in the binder was insufficient to hold the powders together to sustain the swelling force during debinding. Thus, the dimensions of the PIM compact will not be consistent after debinding. When the amount of PP was increased from 30 to $40 \mathrm{wt} \%$, the repeatability was improved.

Based on the results above, it is thus suggested to monitor the amount of swelling and the repeatability of the debinding behavior for each binder system when selecting or designing a binder composition.

\subsection{Distortion}

The degree of distortion or sagging of the specimen provides another criterion for selecting debinding parameters. The curve shown in Fig. 11 indicates that the amount of sagging is significant at $50^{\circ} \mathrm{C}$ and $60^{\circ} \mathrm{C}$. These temperatures are still lower than the melting points of pure $\mathrm{PW}$ and SA, as shown in Table 2. However, it should be noted that the melting points of binder components usually decrease after kneading [3,6]. The three endothermic peaks observed in our DSC tests indicate indeed that the melting points of SA, PW, and LDPE in the kneaded feedstock are lowered to 43 , 59, and $97^{\circ} \mathrm{C}$, respectively. Furthermore, the melting point of a polymer is usually reduced by the presence of the solvent [4]. Thus, it is conceivable that when the solvent temperature is $50^{\circ} \mathrm{C}$, the compact may slump or distort due to the softening of the compact. Since the binder extraction rate was not significantly reduced when the debinding temperature decreased from 50 to $45^{\circ} \mathrm{C}, 45^{\circ} \mathrm{C}$ was selected as the optimal debinding temperature for specimen No. 4 in this study. This example shows 
that an adequate debinding temperature can be determined by using the sagging test and is usually no higher than the melting point of the major binder components in the kneaded feedstock, such as PW in this study.

\section{CONCLUSION}

A laser dilatometer has been developed and is able to measure the in situ dimensions of powder injection-molded compacts during solvent debinding. Expansion of specimens was observed when molded compacts were immersed in heptane and hexane. The amount of expansion increases with increasing temperature, decreasing molecular weight of the solvent, and increasing amount of the insoluble backbone binder.

Soluble binder components, paraffin wax and stearic acid, when dissolved in the solvent, will cause the solution to increase in volume. However, this dissolution is not responsible for the swelling of the compact during debinding because instead of forming swollen gels, they form liquid solutions.

The relative debinding rate increases as the amount of backbone binder decreases. However, with too little backbone binder, such as $30 \mathrm{wt} \% \mathrm{PP}$ in the binder, the green strength is not high enough to hold compacts together, as was indicated by the poor repeatability of the dilatometer curves during debinding. When the PP content increases to $40 \mathrm{wt} \%$, the debinding behavior becomes repeatable.

The in situ measurement on the specimen length, along with the sagging test, provide two worthwhile references when designing a binder system and an adequate debinding schedule.

Acknowledgements - The authors gratefully acknowledge the support for this project by the National Science Council of the Republic of China under contract No. NSC85-2216-E-002-030.

\section{REFERENCES}

1. German, R. M., in Powder Injection Molding. Metal Powder Industries Federation, Princeton, NJ, 1990, p. 281.

2. Hwang, K. S., Rev. Particulate Mater., 1996, 4, 71.

3. Lin, S. T. and German, R. M., Powder Metall. Int., 1989, 21, 19.

4. Billmeyer, F. W., Jr., Textbook of Polymer Science. John Wiley and Sons Inc., New York, 1984, p. 151.

5. Nanjo, I., Achikita, M. and Matsuda, S., in Proceedings of the 1993 Powder Metallurgy World Congress. Japan Society of Powder and Powder Metallurgy, Tokyo, Japan, 1993, p. 241.

6. Hwang, K. S. and Hsieh, Y. M., Metall. Mater. Trans., 1996, 27A, 245.

7. Tsai, D.-S. and Chen, W.-W., Ceram. Int., 1995, 21, 257.

8. Amaya, H. E. in Advances in Powder Metallurgy, Vol. 1, ed. E. R. Andreotti and P. J. McGeehan. Metal Powder Industries Federation, Princeton, NJ, 1990, p. 233.

9. German, R. M. and Bose, A., in Injection Molding of Metals and Ceramics. Metal Powder Industries Federation, Princeton, NJ, 1996, p. 83.

10. Chung, C. I., Rhee, B. O., Cao, M. Y. and Liu, C. X., Advances in Powder Metallurgy, Vol. 3, ed. T. G. Gasbarre and W. F. Jandeska. Metal Powder Industries Federation, Princeton, NJ, 1989, p. 67. 